\title{
Children's Mental Illness and Family Bonds: A Case Study of a Student with Learning Difficulties
}

\section{Dotta $\mathrm{P}^{1 *}$ and Feijó LP²}

${ }^{1}$ Master in Clinical Psychology, University of Vale do Rio dos Sinos/Unisinos, Brazil ${ }^{2}$ Doctor in Clinical Psychology at the University of Vale do Rio dos Sinos/Unisinos, Brazil

*Corresponding author: Patricia Dotta, Psychologist, Master in Clinical Psychology at the University of Vale do Rio dos Sinos/Unisinos, Specialist in Neuropsychopedagogy and Neuropsychology, Teacher of Psychology at the Uniftec University Center in Bento-Gonçalves, Brazil, Email: patricia.dotta5@yahoo.com.br

\section{Research Article}

Volume 6 Issue 1

Received Date: February 17, 2022

Published Date: March 01, 2022

DOI: $10.23880 / \mathrm{mhrij}-16000166$

\section{Abstract}

Objective: To understand motives for the learning difficulties of a child with a history of school failure and its relationship with family bonding and yet to apply a neuropsychopedagological intervention.

Methodology: it's characterized by a trial of clinical case with qualitative, exploratory and longitudinal approach. The clinical interpretation was performed through observation, in light of psychoanalytical theory. Were used as instruments: ludic diagnostic interview, the intelligence exam Wechsler Scale Intelligence Test for children WISC-IV, the children's narratives MacArthur Story Stem Battery, the questionnaire Child Behavior Checklist CBCL (Teachers Version-TRF Teacher Report Form, and the H-T-P test: Home-Tree-Person). Projective design technique.

Results: the contestant is 13 years old, and presents severe learning difficulties. Worth mentioning is the presence of psychological suffering, predominantly permeated by internalizing symptoms: anxiety and depression. There are indicators of cognitive commitment, although academic performance is satisfactory. The participant presents parental representations without indicators of affection, protection and help. And weaknesses in his personality structure are evidenced.

Discussion: the cognitive deficit of the participant may be a symptom of a family arrangement that is not satisfying to the child's needs. This study suggests binding frailty could be triggering psychological suffering that is disturbing cognitive development. The neuropsychopedagological intervention has enabled the family rescue and reorganization of the bonds, the potentiation of cognitive abilities as the verbal understanding of the student and assured him that the school provides him with an affective and welcoming listening, in the face of fragile family relationships.

Keywords: Psychoanalytical Theory; Child Behavior; Anxiety; Depression; Cognition

Abbreviations: LD: Learning Disorders; PRI: Perceptual Reasoning Index; VCI: Verbal Comprehension Index; WMI: Working Memory Index; PSI: Processing Speed Index; CBCL: Child Behavior Checklist; ICF: Informed Consent Form.

\section{Introduction}

Childhood is considered an important phase of human development, once it presents itself as structuring in the formation of the future adult. This phase is tangentialized by 


\section{Mental Health \& Human Resilience International Journal}

several factors, such as physical, intellectual and emotional [1]. At this stage of the development, the relevance of family bonds, quality of social environment and emotional aspect to maturing the psychical apparatus is highlighted, being these factors also influencers in the ability of the child's learning environment. According to Winnicott DW [2] child mental health can be understood as the quality of the family bond that allows the development of human subjectivity. As well as the formation of healthy bonds can serve as a protection factor for the development of child mental health [3]. For Dumas JE [4] there are two large groups of mental disorder in childhood. The first of them refers to the disorders of psychological development and in the background behavior and emotional disorders. The disorders of psychological development are presented at the beginning of the first or second childhood, with characteristics of commitment or delay of functions associated with the biological issues and lack of maturing of the central nervous system.

The second class, is normally presented during the first five years of life, and can come accompanied by a cognitive deficit and a specific delay of motricity and language and psychosocial factors, which are tangentialized by the dysfunctions in family life, inducing situations of stress and environmental factors, like problems in the community (urban violence) and types of abuse (physical, psychological and sexual). [5]. Another point to be problematized are the "behavioural problems", being these understood by conducts or actions considered socially inadequate, which represent behavioural deficits or excesses that harm the interaction of the child with the pairs and adults of their coexistence, associated only with the individual, these behaviors can be named externalizing or internalizing problems $[4,6]$.

According to Martins SK [7], the intensity of impacts caused on children due to marital adversity will depend, especially on the way she's exposed to situations. This could trigger psychic symptoms like anxiety, depression and aggression, but also contribute positively in other ways, as in the development of the ability to solve problems. Among the externalizing problems are gathered in these item characteristics as impulsivity, physical or verbal aggression, agitation and provocation. The internalized ones are classified as concern in excess, retraction, sadness, shyness, insecurity and fears are often manifested in disorders as depression, social isolation and anxiety [4,8]. According to Pedersen IH, et al. [9]. The problems of externalizing behaviors are more often in boys. The girls present fewer problems in general and the complaints refer to internalized behaviour and such psychopathology can contribute to cognitive failures in children [10].

These differences can be related to gender, since the boys are usually more active, aggressive, independent and girls are more passive, less aggressive and have better social interactions [9]. In this sense Martins SK [7] It is suggested that the child's psychic suffering is related to his family context and, besides, when the youngest member of the family presents psychic illness the entire family dynamics is modified [7]. In addition, other factors may also contribute to the emergence and maintenance of behavioural problems, such as socioeconomic factors, family issues, such as family size, parental psychopathologies, severe disciplinary practices, psychological violence, genetic factors, individual characteristics, among others [11-14]. According to these authors, mental health problems are present in greater numbers in children exposed to vulnerability factors, such as low levels of education, living in places without assistance and with poor security, and being susceptible to different forms of violence.

When the child is in psychological suffering the learning process can be harmed [15]. The diagnosis of the difficulties and the disorders of learning difficulties are essentially done from the academic performance of the child [16]. But also, the relationship between cognitive capacity and the feelings that the individual has of himself, as well as delays in child development may be taken into consideration [17]. Besides, the diagnosis involves interdisciplinary in at least three areas, neurology, psychopedagogy and psychology [16]. In Learning Disorders (LD), normal patterns of skill acquisition are disturbed since the early stages of development, and are acquired due to lack of adequate stimulation or any form of trauma or brain disease. In addition, the disorder must be present since the first years of schooling, persists, despite adequate specific care.

Cognitive assessment ruled out mental disabilities, causes such as difficulties in the route and/or secondary were ruled out, and there is history of family background with learning difficulties. The LD has a dimensional nature, that is, particularly affects reading, and occurs along a gravity continuum $[16,18]$. Learning difficulties though, are characterized by disorder or dysfunction in the process of learning [16]. The authors Rotta NT, et al. [16] suggest some proper characteristics of learning difficulties. First, the child with a learning struggle has an incompatible performance with cognitive ability expected for his age and his difficulties are far greater than presented by his colleagues. Such difficulties are often transient and can be minimized when diagnosed in preschool, should be worked by respecting their limitations and allowing these children to also interact with knowledge [16].

Although there is a relationship between learning disorders and learning difficulties, it is of fundamental importance to know them apart, not making the mistake of always associating one thing to another [19]. Besides, 


\section{Mental Health \& Human Resilience International Journal}

the learning difficulties relate to an individual who has a different way of learning [20]. In this sense, positive family interaction, their communication and the presence of healthy bonds enables the development of child mental health [4]. Therefore, the better the quality of family relationship the smaller will be the indicators of child psychological suffering and best academic performance [21]. Such development happens because the family is the child's support, also enabling the development of their social and cognitive skills, assisting in their academic performance. In short, family guidance and support contribute to a satisfactory performance of the child in his school environment [22].

Thus the possible learning problems can have a direct relationship with the problems in the family bonds [23]. According to the study carried out by Souza LBD, et al. [22] it was possible to identify emotional suffering characterized by learning problems, when children and teenagers are neglected by family and/or school. In the face of this stalemate appears the performance of neuropsychopedagogy that takes primordial role in the evaluation, identification and intervention of such learning difficulties [24]. Neuropsychopedagogy fully notices the individual, with cognitive abilities and inserted into a social environment, where it influences and is influenced by it. That's why it's now to clarify a little bit about how neuropsycopedagogy understands and acts in the face of learning difficulties [25].

Besides, the neuropsychopedagogist assists in building relationships between school,family and student, as itenlarges the abilities to intervene in the statement of new educational procedures and creatively build neuropsychopedagogical alternatives [26]. Such interventions promote a more humanizing school environment, as it also resignifies educational practices so that can establish and promote significant pedagogical practices, more transformative and emancipatory [27]. So, actions that promote skills and capabilities for cognitive and/or emotional development of children in the context of this problem related to learning are essential for the student to achieve the necessary advantage in terms of formal knowledge. Besides, neuropsychopedagogy can provide the guidance needed for the organization of family bonds [27]. Thus, the aim of this paper was presenting an understanding of the reasons for the learning difficulties of a child with a history of school failure and its relation to family bond and yet, applying a neuropsychopedagogical intervention built by the author.

\section{Methodology}

It's a clinical case study with qualitative, exploratory and longitudinal approach.

\section{Instruments}

\section{Ludic Diagnostic Interview}

The Ludic Diagnostic interview aims to understand the reality and psychological functioning of the child. In this activity, the toy becomes a mediator that enables children to represent their fantasies, project their conflicts and update their relationships in the here and now [28]. During the activity, it will seek to analyze some factors, namely: the way the child chooses toys; motor skills; creativity and symbolic resources; tolerance to frustration; adequacy to reality; the modality of play, among others. This activity assesses children in an appropriate way, respecting their mode of expression and seeking to understand them in their reality: the symbolic and ludic universe [28].

\section{Wechsler Intelligence Scale for Children WISC- IV}

The WISC-IV intelligence test is aimed to assess the intellectual capacity of children and the process of problems resolution. The Scale is meant to 6-year-old children and 0 months to16-year-old and 11 months. The instrument is composed of 15 subtests. The main subtests of the Verbal Comprehension Index (VCI) are Similarities, Vocabulary and Comprehension; and the supplementary ones are Information and Word Reasoning. The subtests related to the Perceptual Reasoning Index (PRI) are Block Design, Picture Concepts and Matrix Reasoning; and the supplemental is Picture Completion. As for the Working Memory Index (WMI), the subtests are Digit Span and Letter-Number Sequencing; and the supplemental is Arithmetic. Finally, for the Processing Speed Index (PSI), the subtests are Coding and Symbol Search, and the supplemental is Cancellation. The average of reliability coefficients of WISC-V subtests varies between 0.79 and 0.90 . It presents expiration indicators and adequacy in the internal structure [29].

\section{MacArthur Story Stem Battery}

This instrument composed by 14 (fourteen) narratives for the purpose of understanding moral development, as for emotional expression, pro-social behavior, parental representation, aggression, control, temper, nature of defensive processes, emotional regulation and conflict resolution strategies [30]. The MSSB instrument was translated into the Portuguese Language, as well as its classificatory system. The MSSB Coding Manual presents six categories for evaluating the narratives: the content of the themes: interpersonal conflicts, empathic relationship, aggression and moral themes; the emotional codes of the narratives: issues of danger, safety, destruction of objects, the child's power, reaction, separation, and hope, emotional 


\section{Mental Health \& Human Resilience International Journal}

inconsistency, the first reaction and the final content of the narratives; parental representations: triangulation, discipline and control, positive representation (protective, affectionate, caregiver and help) and negative representation (punitive, rejection, and ineffective); performance codes: control, anger, joy, anguish, interest, sadness, narrative coherence and performance style; avoidance strategies: exclusion, repetition, denial and family breakdown; and dissociation codes: escape from painful subjects, identification with aggressors, fantasy proneness, distraction, absorption, and traumatic material [30].

The items to be evaluated, according to the manual, have established specific criteria for their score, that's why some items are rated in present (1) and absent (0) and others evaluated from 0 to 10 (zero to ten), according to the intensity presented in children's narratives. For example, the item aggression is classified according to the kind of aggression that is described by the child in the narratives, being scored $0-5$ when 0 (zero) is absent for such category and 5 (five) represents the higher intensity of aggression and damage. During the instrument application, the Therapeutic Family is used, with the intent to facilitate the expression and projection of the child in the dolls when narrating the stories.

\section{Child Behavior Checklist CBCL Questionnaire (Teacher Version-TRF Teacher Report Form)}

The instrument is the worlds most used to identify mental health problems in children and teenagers from parent information are the Child Behavior Checklist (CBCL). In this study, the version for teachers was used [8]. The instrument offers perception of mental health problems in children and teenagers according to information provided by the teacher. The TRF is indicated for children and teenagers aged between 6 to 18 and understands 138 sentences, among them 118 concerning behavior problems and 20, social competence. The questionnaire assesses the child's academic performance, in the teacher's perspective. The average normal academic performance is between 40 to 65 points. Besides, it assesses emotional reactivity syndromes, anxiety/depression, somatic complaints, attention problems, aggressive behavior and sleep problems and social problems, problems of thought and violation of rules. From the scores obtained on these scales, the child can be included in clinical ranges, borderline or normal, regarding global function and internalizing and externalizing profiles.

For inclusion in the internalizing profile, isolation items, somatic complaints, anxiety/depression are considered and for inclusion in the externalizing profile, the assessed items are violation of rules and aggressive behavior. The normality of externalizing and internalizing symptoms between 50 and 60 points. The version used from the TRF to Brazilian culture was adapted by Bordin IAS [31]. There's no data published on reliability and validity, however, it's observed that in the study performed by Ang RP, et al. [32] that comparison of behavior problems affected by the guardians (CBCL) and teacher (TRF) in the first phase of the research showed correlation with less than $1 \%$ of significance, as observed in other international studies [32-35].

\section{H-T-P Test: House-Tree-Person Projective Design Technique}

HTP has as a goal to understand aspects of the individual's personality as well as the way this individual interacts with people and with the environment. The test stimulates the projection of elements of personality and conflict areas within therapeutic situation and provides an understanding and dynamic of the individual's characteristics and function [36]. The instrument is destined for individuals over eight years old and proposes the accomplishment of three sequential drawings - a house, a tree and a person, whom must be drawn in separate leaves, using pencils and rubber. The application proposes, too, that an inquiry about characteristics and descriptions of each drawing is performed. Besides, HTP is one of the most used tests in the clinical context in Brazil for evaluation of clinical populations [37]

\section{Participant}

The study counted on the participation of a student: Sandro (fictitious name), 13-year-old, is enrolled in the fifth year of elementary school of the municipal public elementary school system in southern Brazil. He resides with his parents and a younger sister ( 5 years old). He was presenting history of school retention, and although attending the resource room presents severe difficulties in the alphabetization process. The boy has difficulties in writing and reading words and sentence formation. In this sense, the teacher suggested the attendance to better understand these difficulties, as well as professional aid for intervention and posterior personal progress.

\section{Data Collection Procedures}

The present study was developed in a State Elementary School within the state of Rio Grande do Sul, in the months of April to May 2019. Inside the school, the Psychology and psychopedagogy sector presents as services, guidance and support for students who have learning difficulties. The students who present learning difficulties are invited to participate in individual and/or in group psychological guidance. The present student, from the demand requested by the senior professor, has forwarded him to the psychology service, due to its severe learning difficulties. The student was invited to participate in neuropsychopedagogical 


\section{Mental Health \& Human Resilience International Journal}

activities and application of tests during the period of class. The student's participation happened after parent consent. After signing the term of free consent cleared by the mother, nine dates were held with the student, with the longing of an hour, in the Psychology room. The Psychology room allowed a suitable accommodation as well as conditions of luminosity and silence.

Besides, four more observations have been held in class with five hours each. The observation in class has understood what the student's behavior is like in the process of socializing and also of learning. And the teacher answered the TRF questionnaire for evaluation of possible psychological components, academics and behavior problems. Two dates were held with the mother: the first to perform an anamnesis interview to understand the student's child development. As well as to understand the family dynamic and how the organization of the tasks, routines and activities of the student happened. On the second date the return of the study for the student's mother was performed.

\section{Data Analysis Procedures}

The interpretation of the HTP, WISC-V, TRF and MacArthur Story Stem Battery instruments, were made according to specific guidance of each manual used, respecting methodological criteria. Qualitative analysis was used to relate whether the difficulties of learning and possible psychopathologies of the student's development are related to the possible problems in the family bonds. Besides, the clinical interpretation was performed through observation, in the light of psychoanalytic theory [38-40]. Besides, psychological tests WISC-V and HTP are psychological tests validated by the Psychological Testing Assessment System (SATEPSI) and they present quality, faithful and technical reliability.

\section{Ethical Procedures}

This study was forwarded to the school institution ethics committee and the Department of Education of the county, aiming to clarify what the objectives are and perform a detailed exposure of the project and its specifications, in order to fulfil ethical procedures. The student's mother filled the term of Informed Consent Form (ICF), which clarified the objectives of the study and the contestant signed the term of consent and therefore agreed to participate in the research. Confidentiality regarding identity and information was ensured, as well as the right not to participate or suspend participation at any moment. If the interventions caused any discomfort, the activities would be stopped. The right to not answer was guaranteed, and if wished will be able to seek psychological aid with a psychologist of the city health service: CEMAPS: Center of Psychosocial Attention, this would be forwarded. Besides, the study is in accordance with the 196/96 CNS Resolution and takes into consideration the three principles: respect for people (Autonomy), for benefit and justice.

\section{Results}

\section{Clinic History and Neuropsychopedagogical Intervention for Learning Difficulties}

In this section the process of intervention with Sandro was described, bound to the observation of the manifest and latent contents from the verbalizations between the professional and the patient during sessions and the logical activities that promoted the boy's internalized development $[41,42]$. It's worth mentioning that at this time a qualitative report will be presented. Sandro lives with his parents, has a five-year-old sister. His parents are separated, however, live in the same house. Sandro was born by a normal delivery and started walking at 11 months old. Besides, he's in good health. According to his mother, the child's pregnancy went through without any trouble. Sandro usually plays with his cousin and his school friend. When he's home, he watches TV and plays with his pet. During the afternoons does his homework and goes to bed early. At school, he goes to the resource and diversity room and gets psychotherapist care in an institution. The boy presents history of family violence, suffered severe physical and verbal aggressions from his father. After therapeutic process, the father has diminished the physical aggressions, however, according to his mother, verbal aggressions usually happen.

His mother reports that Sandro is a sociable boy joined the school with severe learning difficulties. According to his mother, his former school teacher didn't follow him. He couldn't write, his notebook was blank, he couldn't read or write. His teacher offers activities that are developing alphabetization. The centrality of the interventions of the current teacher for the development of the student's learning is highlighted. She usually presents a warm and affectionate attitude in the face of Sandro's mistakes. Sandro, in class, performs different activities from his classmates. The class is already literate, he still needs activities that develop the ability to read and write, for example, and he seems to show a disinterest for activities that are harder. However, he is social with his classmates, makes friends and shows himself interested in activities.

A central question of Sandro's teaching process is his perception of "dumb" and inappropriate. This feeling pervades all the activities in which during this job aimed to promote. Sandro always highlighted he couldn't do it, because he was "dumb". The interventions have been promoting the autonomy of this one, and encouraging him 


\section{Mental Health \& Human Resilience International Journal}

to perform. There is the need of stimulation and continuous motivation. When he's stimulated, Sandro usually does the activity, however, shows important indicators of disinterest in more difficult activities.

\section{Assessment of Psychological Constructs}

During the performance of the tests, Sandro understood the directions of the tests (MacArthur Story Stem Battery; WISC-IV Intelligence Test and HTP Personality Test). However, the error rate was high in practically all of them. Most of the time he remained silent, often calls himself "dumb" and attributed negative adjectives to himself. But he revealed himself always very helpful and kept the agreement all along. In the attendances using the time of the diagnostic game, it was noticed that Sandro usually takes orders and carries out activities unquestioning. Besides, difficulty in symbolizing and developing creativity were observed. He performs simple and concrete activities. For the evaluation of family bonds MacArthur Story Stem Battery [30] was used. According to the instrument, failure in the binding processes are observed, the boy presents a representation of his parents without indicators of affection, care, protection and help. Sandro usually solves conflicts by using adult strategies. His stories are short, uncreative offering minimal and necessary amounts to tell the story. When his parents show up in the history, they show a behavior of indifference. In the narratives, the presence of feeling of sorrow is observed, and in all stories the applicator needs to stimulate his speech.

During the HTP application, Sandro drew it fast. He seemed to want to get rid of an unpleasant task. He drew everyone and waited for the applicator's approval. The results of the drawings evaluation suggest a difficulty dealing with environmental pressures, once Sandro presents strong need for safety, affection and protection and understands its environment as restrictive and tense. He tends to present a retraction behavior and oppositionist tendencies. There are indications of a stricter and intransigent style, which compensates feelings of inadequacy and insecurity and presents a profound need for readiness to face everything directly and firmly. There are indications that the evaluated individual tends to seek more satisfaction in fantasy than in reality, which means it presents impoverished contact with reality. This shows the presence of psychological suffering indicators [43]. Besides, a difficulty imagining family relations is observed, since for him the quality of family relations is fragile and without affection, observing important difficulties in approaching among his family, so it turns out he can't express the feelings of affection properly. Yet the strong need for safety stands out, which suggests regression. Cognitive fragilities have been perceived in the HTP, which means, his cognitive should be more developed for his chronological age [43]. For the most faithful assessment of intelligence, the WISC-IV Intelligence Test was used. The results can be visualized on Figure 1.

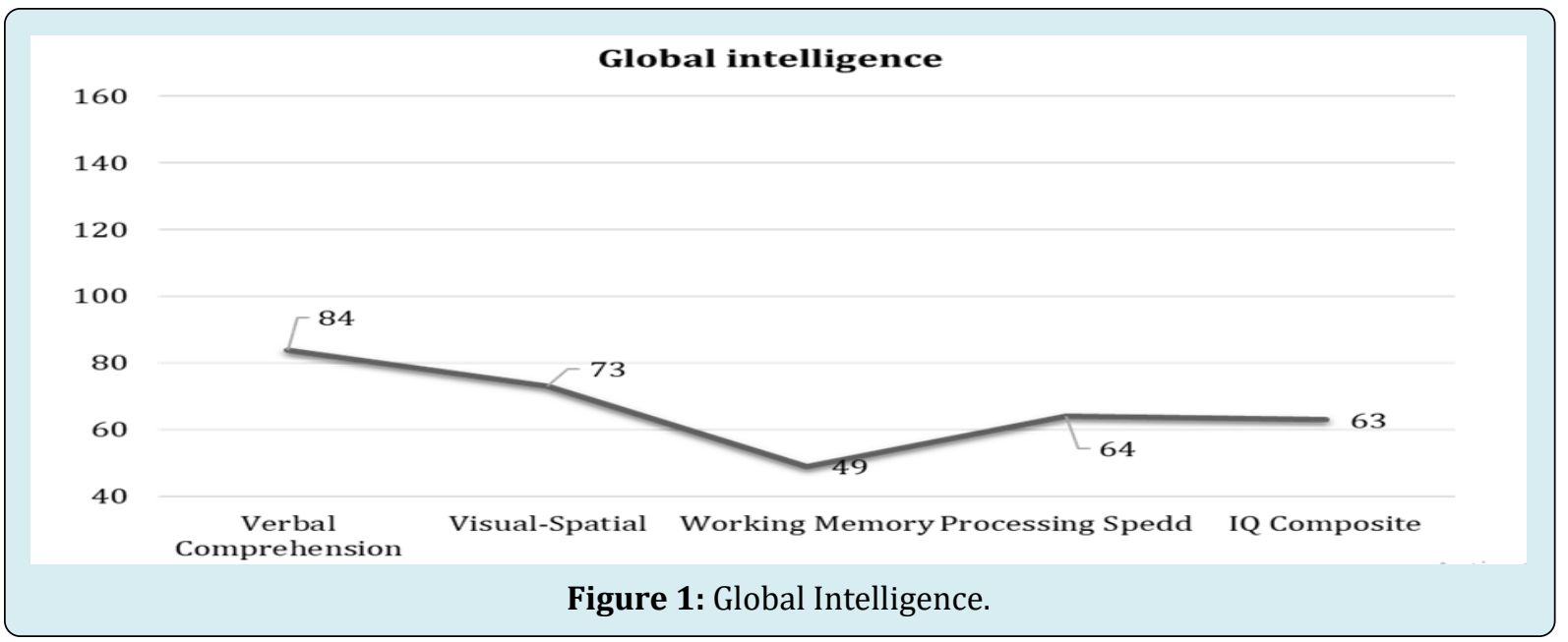

It is observed that due to major failures in cognitive processes, all scales were classified with extremely low index. The verbal compression scale shows a difficulty in the face of logical reasoning and verbal conceptual formation (abstract thinking). It presents inductive reasoning failure, with identification of essential and non-essential aspects; learning ability, language development. In addition, there is a lack of resourcefulness in the capacity for common sense, in social and moral judgment (judgment), in practical knowledge and social maturity: it does not have an adaptation of the domains acquired in the activities of daily and practical living, in the knowledge of sociocultural norms, and in the ability to assess past experience. In perceptual organization is observed with a deficit and can't perform analysis and synthesis-abstract reasoning, visuospatial conceptualization capacity, visual-motor spatial coordination, organization and 
perceptual speed and has no strategies of problem/planning solution.

Operational memory is the scale with greater difficulty. Operational memory evaluates the capability of attention and concentration and specific cognitive dominions to: retention of immediate memory (digits in the direct order); memory and ability to reversibility (digits in the reverse order); concentration, short-term memory; auditory memory and stress tolerance. It is noted a significant difficulty in the ability of information retention capacity picked up by sensory memory for short-term memory. Finally, there is the speed of processing with the total of 64 points, indicating lack of selective attention, concentration (resistance to distractibility) and lack of motor persistence in a sequential task and absence in the ability to learn, inefficiency and mental inflexibility. According to the Child Behavior Checklist CBCL (Teacher Version, TRF Teacher Report Form), the school performance in the perspective of the teacher, Sandro, performs properly (44). The other scales can be visualized on Figure 2.

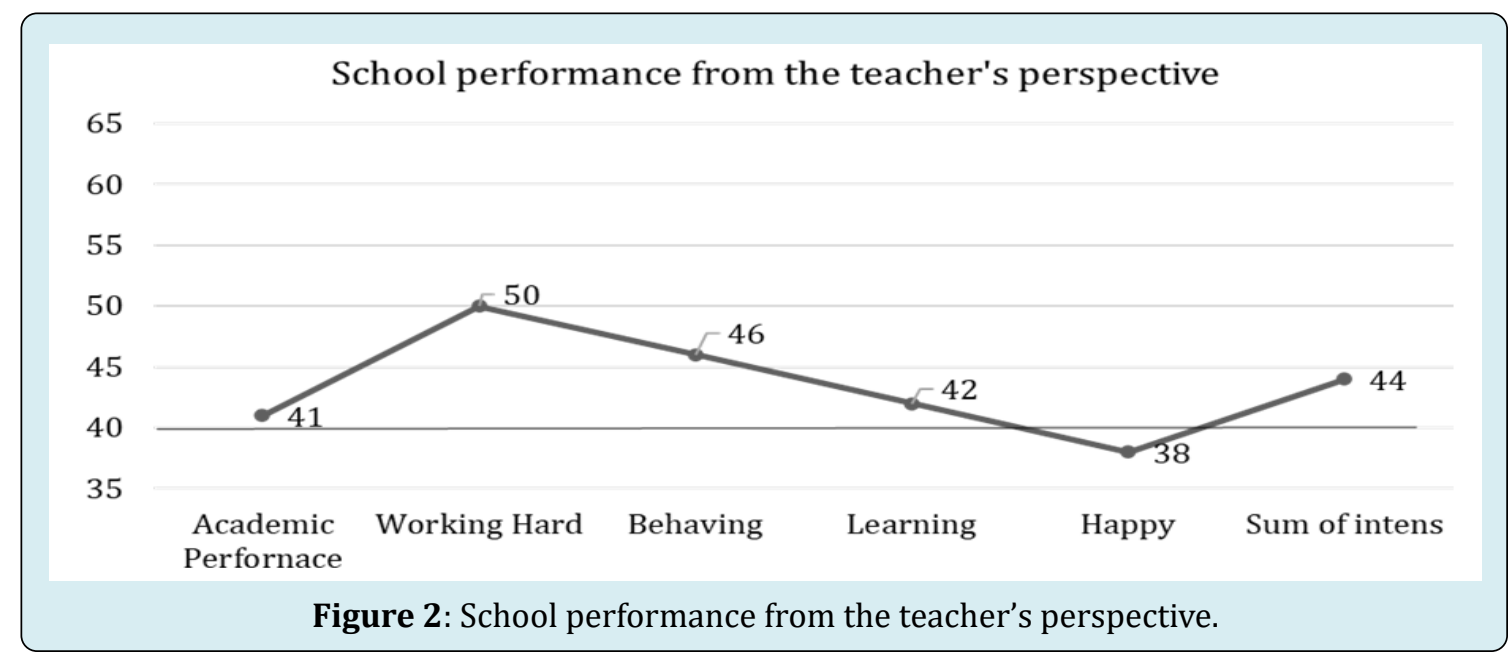

The student shows effort (50), and learning capacity (42). It shows proper behavior in class (46). However, evidence of lack of feelings of happiness (38). Sandro is being literate and despite the difficulties in the process, it is in the process of evolution. Sandro presented internalizing symptoms above average, indicating the presence of psychological illness. The externalizing symptoms are at the limit to developing a psychopathology. Below follows chart 3 to visualize the indicators.

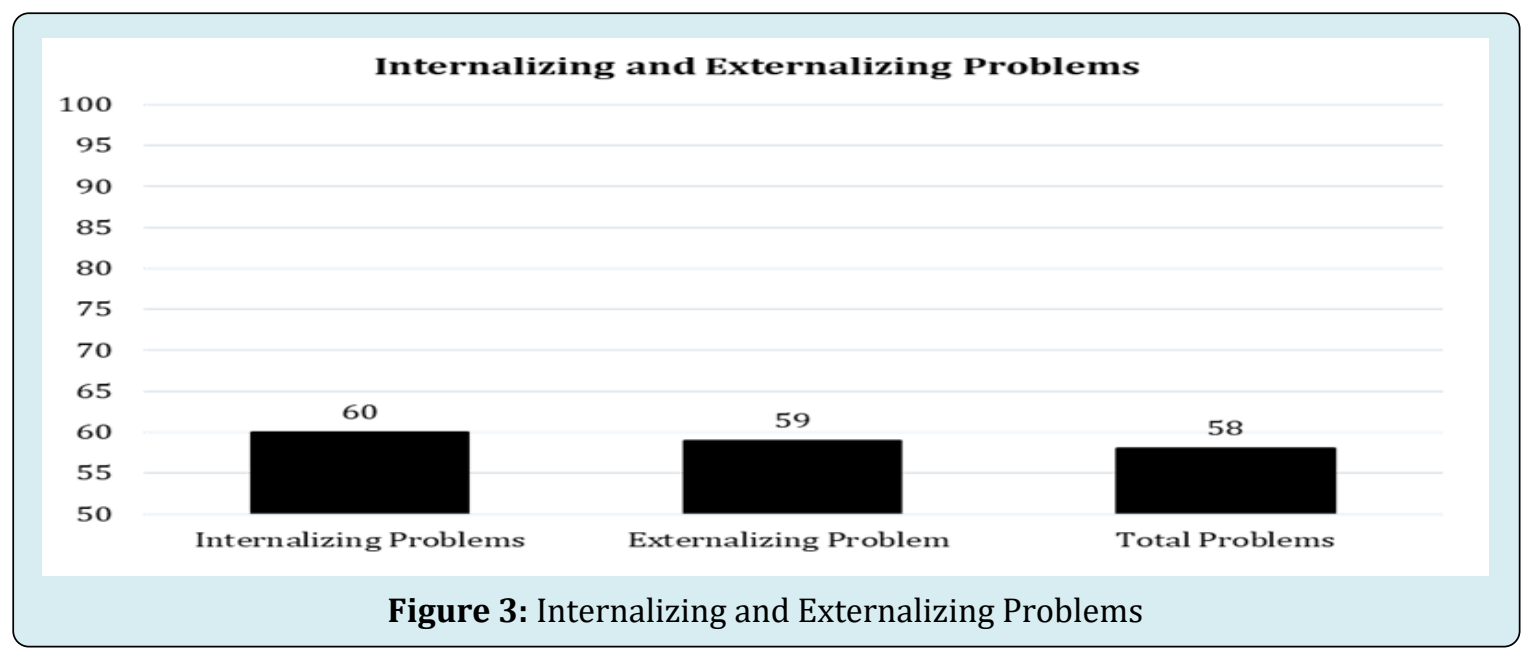

Figure 3 suggests that Sandro is developing a possible psychological suffering (58). The internalizing symptoms present greater indicators, which suggest the presence of depressive, anxious symptoms and somatic complaints.
The presence of cognitive failures added to the high index of internalizing and externalizing symptoms suggests a relationship between such variables. 


\section{Mental Health \& Human Resilience International Journal}

\section{Discussion}

The learning problems are recurring and they deserve a highlight, in terms of discussion and intervention, for even though they've slowed down in statistical yearbooks, the prevalence of disorders and learning difficulties varies between 5 to $15 \%$ among school-age children, in different languages and cultures [18]. In Sandro's case, despite a satisfactory academic performance, one observes severe learning difficulties linked in cognitive processes, specifically in abstract thinking. His intelligence has been classified as extremely low for his schooling and his age group [29]. According to Piaget J [44], cognitive development is a construction, and abstraction is the last indicator to be conquered at the formal operational stage. Sandro is still at the concrete operational stage and therefore lies outside the normality of cognitive development for his chronological age. It is assumed, as a hypothesis, that the learning difficulties, linked to failure in Sandro's abstract thoughts are associated with parental frailties, and of personality construction. This result corroborates with Silva MASE, et al. [45] confirming that the weakening of affective bonds, relational, or linked to violence reverberates in negative reflexes that harm cognitive development and contribute to increase the difficulty of learning.

Besides, the presence of psychological suffering prevents normal development of Sandro's cognitive processes. Such a finding corroborates with the results of Ramires VRR, et al. [3], suggesting that sadness and depression, as well as anxiety associated, in a significant way to parental stress variable and harm learning. The difficulties of learning in this case, represent a form of inadequate and inferior selfrepresentation, which attributes only negative aspects of oneself, with the presence of feelings of sadness and high indicators of internalizing symptoms (anxiety, depression and somatic complaints). So the construction of a self, integrated, capable and self-employed is a challenge so that teaching-learning processes can happen. The process of reading and learning can represent a new psychic position internally and constitutes a challenge and a mental and psychic effort. Sandro lies in the process of alphabetization, and therefore sees himself far from the performance of other classmates. It's common in the alphabetization phase, for Sandro to face anguish as an effect of the demands to which he must fulfil [16].

The school in turn shows itself concerned about maintenance of the school calendar and goals to be achieved. These social demands put the school and the teacher paradoxically, in confrontation in the children's learning process. Some questions are raised, "How to think the desire to learn in Sandro that even though being in fifth grade, begins school life?" "What does it represent, in the perspective of desire, the learning process for school and for Sandro?" "How to understand Sandro's admission in the literacy process and the place of his desire in the learning process?" [46]. In addition, he identifies himself as "dumb", so he could not "start learning" because he would lose his already known identification. This position may arise from fragile family relationships, permeated by interests in physical and verbal aggression. The deconstruction of this "dumb" place becomes an important factor for the teachinglearning process, but also for the development of personality factors. Therefore, it is understood that Sandro's cognitive deficit is a symptom of a family arrangement that does not satisfy the student's affective needs. Such a finding is in line with Faccini A, et al. [47] showing that fragile and inconsistent bonds, perpetrated by conflict, are indicators of insecure attachment, which make the symbolization capacity difficult and by consequence abstract thoughts. It's important to point out that the role played by the family represents in the education of the child is a primordial factor in the formation of self-esteem, and consequently in learning.

The family environment provides the first learning, having essential function in the development and/or inhibition of this process [4]. Confidence, nominated as one of the aspects that facilitate Sandro's learning, in the present research, can be easily facilitated from the parents' empathy, establishment of a warm, careful relationship, favouring a greater socialization and consequent learning. Such hypothesis corroborates with Ferreira AA, et al. [48] when they claim that family support collaborates in the prevention of developing learning difficulties and in the decrease of psychological suffering. Sandro would need a warm and human environment to stimulate the development of a sense of self capable, autonomous, which provides him with the possibility of learning from his mistakes. The author Lasneaux MV [49] points out that children with learning difficulties, can be brilliant, creative and talented in other areas, but in our society, where the academic performance is highly valued, these children feel like failures, mainly if compared to the children who present a better cognitive development, thus creating a much more accentuated blockage in the learning process.

It stands out in the present study, that one way to deal with Sandro's difficulties is to work with activities that involve verbal understanding, because that's what's best preserved. The student needs activities and tasks that are operationalized in a concrete way, because he presents difficulty symbolizing and organizing "inner world" reflecting such difficulty in the teaching-learning processes. An interesting idea is to think that at school the student Sandro can guarantee the construction of human psyche, which provides a warm, affective listening in front of fragile family relations. As neuropsychopedagogical interventions 


\section{Mental Health \& Human Resilience International Journal}

for Sandro's emotional development process, continuing the psychotherapeutic process for the deconstruction of the negative representation that he possesses of himself is suggested. Besides, the strengthening of family relations, by building bridges among the teacher and family and school psychologist, is essential, to reinforce the representation of a more integrated, stable personality, and a sense of self capable and autonomous.

In this perspective of strengthening bonds, the relationship with his current teacher is essential. As interventions, working with sustained attention exercises; observing the student's seat and tasks that distract him so that they are modified and avoided; giving instructions before the beginning of the task and verifying if the student understands them, asking for his feedback; constantly supporting the student; giving positive feedback, immediately after performing tasks, offering positive reinforcement; working with stimulating materials so that they catch the student's attention and provide opportunities for learning; working with recordings, oral activities, dynamics, markers, post-it notes, among other resources is suggested; not criticizing negatively; establishing intervals between activities; waiting for the student's timing; allowing movement and displacement during school activities. The present research, through neuropsychopedagogical intervention, did not focus on the preventive nature of family support, but on the identification of evidence that may be impairing school performance. In this sense, the interventions carried out with Sandro endorsed areas that the extensive scientific production recommends for the subject, that is, working with cognitive and executive functions in learning, combined with the importance of emotions and the investigation of manifested symptoms [18,50-54].

Learning problems are not unique factors of Sandro, because the most harmed tasks are those that involve a basic reasoning, characteristic of the development process, so family agents may also have failed in the support of this individual [3]. Neuropsychopedagogy even proposes Sandro to be the author of his learning process and that intervening in the process is to create mechanisms so that the learner can transform reality as well as himself. Also in need of the help of family members in administration and social interaction.

\section{Final Considerations}

This job has aimed to understand the relationship between learning difficulties, of a student enrolled in the public education network in southern Brazil, and family bonds. This study highlights that the quality of family bonds impacts in the student's teaching-learning process. The family environment is one of the factors related to the construction of personality and construction of its representations. Sandro presents failures in the representation of his self, which is constituted as inadequate, inferior and fragmented. The student is in the process of alphabetization, and identifies himself with the position of "dumb". The identification with this place is the result of intra and interpersonal relations the student lives in. Therefore, it is suggested that the difficulties of learning are a symptom of environmental failures and binding frailty. The student's teaching-learning process should take into account Sandro's capabilities, as easiness in front of activities involving verbal understanding and operationalizing them in concrete practices. The stimulation of his potentialities and skills is essential so that Sandro doesn't demotivate himself in the activities that can present difficulty $[55,56]$.

School and family play an essential role in Sandro's personality and teaching- learning development. The student is in the process of learning how to read and write, which psychically represents the ability to understand and read who he is. By running into a sense of disintegrated and negative self, Sandro finds difficulties wanting to learn and perform a reading on his reality. However, the deconstruction of this "dumb" place for the construction of a place of "not knowing" is essential to promote the development of both cognitive and teaching-learning processes. The development of Sandro's potentialities with constant stimuli, aiming at his biopsychosocial and educational development, providing him with the opportunity to build knowledge, autonomy and self-control for the exercise of his citizenship. This study highlights as limitations, the study of a single case, which cannot generate generalizations on the subject involved. Longitudinal monitoring could be performed to measure how Neuropsychopedagogy could help in the deconstruction process of this place from "dumb" to "not knowing". It is worth highlighting that the interpretations do not take into account statistical tests to verify the reliability of the data. The study still suggests a higher investment in researches on this theme aiming such aspect invites new investigations, especially from cultural effects and cultural appreciation of certain kinds of family support or others, since certain aspects can be more or less valued in the school as a result of local culture.

\section{References}

1. Rathus SA (2021) Childhood and adolescence: Voyages in development. Cengage Learning.

2. Winnicott DW (1957) Child and the Family. New Jersey, Tavinstock.

3. Ramires VRR, Falcke D (2018) Risk and protective factors for family ties in southern Brazil. Psychology: Teory and Practice 20(1): 126-140. 


\section{Mental Health \& Human Resilience International Journal}

4. Dumas JE (2018) Psychopathology of Childhood and Adolescence-3. Porto Alegre: Artmed Editorial.

5. Cunha MP, Borges LM, Bezerra CB (2017) Childhood and Mental Health: profile of children using the Child Psychosocial Care Center. Changes Psicol Saúde 25 (1): 27-35.

6. Fonseca BCR, Bolsoni Silva AT, Ebner LM (2021) Parents' and teachers' educational practices and children's behavioral repertoirel. General: Interinstitutional Journal of Psychology 14(1): 1-27.

7. Martins SK (2021) Child psychology: Impacts and consequences of marital conflicts. Ibero-American Journal of Psychology 1(1).

8. Achenbach TM, Ruffle TM (1991) The Child Behavior Checklist and related forms for assessing behavioral/ emotional problems and competencies. Pediatr Rev 21(8): 265-271.

9. Pedersen IH, Hyland P, Hansen M, Perera C, Spitz P, et al. (2021) Patterns of childhood adversity and their associations with internalizing and externalizing problems among at-risk boys and girls. Child Abuse \& Neglect 121: 105272.

10. Ferreira AA, Oliveira WGA, Paula JJD (2018) Relationships between mental health and cognitive failures in everyday life: role of internalizing and externalizing symptoms. J Arm Psiquiatr 67: 74-79.

11. Pereira Neto ÉF, Grzybowski LS (2020) Parenting and emotional and behavioral problems: transgenerational analysis based on Murray Bowen's Theory. Thinking Families 24(1): 96-112.

12. Vian M, Mosmann CP, Falcke D (2018) Repercussions of Conjugality in Internalizing and Externalizing Symptoms of Adolescent Children. Psychology: Theory and Research 34: e34431.

13. Silva ACD, Oro GZ, Bossardi CN (2021) Intergenerational aspects of families in situations of violence. Pensando Familias 25(2): 239-255.

14. Wechsler AM, Bution DC, Galvão T, Diniz, JG, Gabriel CB (2021) The mediating role of parenting styles in the psychological adjustment of children and adolescents with chronic diseases. Interaction in Psychology 25(2).

15. de Lima CM (2021) Mental Disorders: Neuropsychology and Learning. Ibero-American Journal of Humanities, Sciences and Education 7(11): 738-764.

16. Rotta NT, Ohlweiler L, dosSantos Riesgo R (2015) Learning disorders: neurobiological and multidisciplinary approach. Porto Alegre, Artmed Editorial.

17. Ohlweiler LYGIA, Rotta NT (2016) Introduction to learning disorders. Learning disorders: neurobiological and multidisciplinary approach, pp: 107-111.

18. American Psychiatric Association (2014) DSM-5: Diagnostic and Statistical Manual of Mental Disorders. Artmed Publisher.

19. Paterlini LSM, Zuanetti PA, Pontes Fernandes AC, Fukuda MTH, Hamad APA (2019) Screening and diagnosis of learning difficulties/disorders-outcome of interdisciplinary assessments. Rev CEFAC 21(5).

20. Baum VD, Rozek M (2021) School learning and pedagogical action in the face of difficulties in the schooling of children in the early years. Application Notebooks 34(2).

21. Silva RMC, Fernandes GNA, Escarce AG, Lemos SMA (2022) Family environment resources and school performance: analysis of associated factors in elementary school adolescents. In CoDAS Brazilian Society of Speech Therapy, 34.

22. Souza LBD, Panúncio Pinto MP, Fiorati RC (2019) Children and adolescents in social vulnerability: wellbeing, mental health and participation in education. Cad Bras Ter Ocup 27: 251-269.

23. Carvalho JD, Duarte MDLC, Glanzner CH (2020) Child mental health care in the context of the Family Health Strategy: an evaluative study. Rev Gaúcha Enferm 41: e20190113.

24. Lima SF, Lopes M, Sousa TSR (2021) Contributions of Neuroscience and Neuropsychopedagogue in the teaching-learning process. University Communication Magazine 1(2).

25. Oliveira DDSF, Rodrigues AP (2021) Attention Deficit Hyperactivity Disorder (ADHD): Neuro Psychopedagogy as an Ally for Girls in Early Childhood Education. Ibero American Journal of Humanities, Sciences and Education 7(9): 907-914.

26. Ferreira S, da Silva FJA (2021) The work of the neuropsychopedagogue: performance, ethics and importance demonstrated through an experience report. Scientia Generalis 2(2):14-22.

27. de Castro FDSL, da Silva SV (2019) The role of the neupsicopedagogue in the empowerment of learning. Mythos Magazine 12(2): 102-114. 


\section{Mental Health \& Human Resilience International Journal}

28. Affonso RML(2009) Ludodiagnosis: clinical investigation through toys. Porto Alegre: Artmed Editorial.

29. Wechsler D (2013) Wechsler Intelligence Scale for Children: WISC-IV: technical manual. 4th ed. São Paulo: Person clinical Brazil.

30. Emde RN, Wolf DP, Oppenheim D (2003) Revealing the inner worlds of young children: The MacArthur Story Stem Battery and parent-child narratives. Oxford University Press.

31. Bordin IAS (1992) Validation of the Brazilian version of the Child Behavior Checklist or Inventory of Childhood and Adolescence Behaviors: preliminary data. Federal University of Sao Paulo, pp: 1-202.

32. Ang RP, Rescorla LA, Achenbach TM, Ooi YP, Fung DS, et al. (2012) Examining the criterion validity of CBCL and TRF problem scales and items in a large Singapore sample. Child Psychiatry \& Human Development 43(1): 70-86.

33. Henz KG, Mendonca Filho EJD, Schneider AMDA, Bandeira DR, Yates DB (2021) CBCL/6-18 and TRF/618: contributions to psychological assessment. Psicol Pesqui 15(3): 1-22.

34. Ferdinand RF, Van Der Ende J, Verhulst FC (2007) Parentteacher disagreement regarding psychopathology in children: a risk factor for adverse outcome?. Acta Psychiatrica Scandinavica 115(1): 48-55.

35. Leung PW, Kwong SL, Tang CP, Ho TP, Hung SF, et al. (2006) Test-retest reliability and criterion validity of the Chinese version of CBCL, TRF, and YSR. Journal of Child Psychology and Psychiatry 47(9): 970-973.

36. Buck JNHTP (2003) HTP: house-tree-person, projective drawing technique: manual and interpretation guide, $1^{\text {st }}$ (Edn.), Sao Paulo, Vector Publisher.

37. Dias Viana JL (2020) Psychometric properties of the House-Tree-Person Test (HTP): Analysis of Brazilian scientific production. Psychology for Latin America 34: 159-170.

38. Coelho D, Cunha EL (2021) Four conditions for research in psychoanalysis. Psychol 32: e190162.

39. Franke D, da Silva JC (2012) From Listening to Writing: The Construction of the Clinical Case in Psychoanalysis. Psicanálise \& Barroco em revista 10(2): 1-20.

40. Gibbs G (2009) Qualitative data analysis: qualitative research collection. Porto Alegre: Bookman Editor, pp: 1-29.
41. Feijo LP, de Oliveira DS (2016) Affective deprivations and bonding relationships: psychotherapy of an institutionalized child. Clinical Contexts 9(1): 72-85.

42. Michelli CRP (2012) Theory_and_practice_of_ neuropsychopedagogy. Indaial: Uniasselvi, pp: 1-33.

43. Papalia DE, Feldman RD (2013) Human development. $12^{\text {th }}$ (Edn.), Artmed publisher.

44. Piaget J (1986) The birth of intelligence in the child. LTC Sao Paulo, pp: 1-212.

45. Silva MASE, Dos Santos JOD, da Costa Cardoso LC, da Silva DF, de Souza Freitas KI, et al. (2021) social vulnerability and its impacts on the learning process. Anais do EvinciUniBrasil 6(1): 255-255.

46. Weiss MLL (2021) Psychopedagogical intervention in school learning difficulties. Wak, pp: 1-168.

47. Faccini A, Ramires VRR (2012) Affective ties and capacity for mentalization in parental alienation. Revista Interamericana de Psicologia/Interamerican Journal of Psychology 46(2): 199-208.

48. Ferreira AA, Oliveira WGA, Paula JJD (2018) Relationship between mental health and everyday cognitive failures: role of internalizing and externalizing symptoms. J Bras Psychiatrist 67: 74-79.

49. Lasneaux MV (2021) Subjectivity and school failure a case study from a psychoanalysis approach. Education in Review 22(2): 93-106.

50. Bauer VB (2021) Neuropsychology of Learning in Executive Functions and Attention. Educational policies and strategies, pp: 53-62.

51. da Silva Pinheiro AB, Pordeus MP (2022) family relations: meanings and attributions for learning in elementary school in a public school in rio grande do nortern. Brazilian Journal of Development 8(1): 237-252.

52. do Prado JA (2021) Emotional education in schools: a guiding ally in the teaching-learning process. Brazilian Journal of Development 7(5): 47173-47183.

53. Mota FM, Silva GTF (2021) The influence of emotions on the learning process. Caderno Intersaberes 10(29): 255264.

54. Osorio S, de Santana AN, Melo MRA (2021) Executive functions in children with learning difficulties. Ciencias Cognicao 26(2): 1-17.

55. Brasil (1996) Resolution No. 196, of October 10, 1996. 
Ministry of Health National Health Council.

56. Bordin IA, Rocha MM, Paula CS, Teixeira MCT, Achenbach TM, et al. (2013) Child Behavior Checklist (CBCL), Youth
Self- Report (YSR) and Teacher's Report Form (TRF): an overview of the development of the original and Brazilian versions. Cad Saúde Pública 29(1): 13-28. 